\title{
A RECLAMAÇÃO NAS ORGANIZAÇÕES DO TRABALHO: ESTRATÉGIA DEFENSIVA E EVOCAÇÃO DO SOFRIMENTO
}

\author{
Fernanda Sansão Hallack \\ Claúdia Osório da Silva \\ Pontifícia Universidade Católica do Rio de Janeiro
}

RESUMO: Este artigo pretende pesquisar a reclamação no discurso dos trabalhadores das organizações na perspectiva teórica de Christophe Dejours. Baseando-se na concepção de que o trabalho é uma das possibilidades do sujeito vivenciar seu sofrimento e tentar dominá-lo, reconhece-se a existência de um sofrimento criador enquanto estado de luta contra a organização do trabalho que muitas vezes conduz ao adoecimento. A reclamação evoca o sofrimento tornando-se uma estratégia de vinculação grupal poderosa enquanto construção de sentido intersubjetivo através dos laços discursivos, na tentativa de resistência grupal à doença. Um forte elo de união entre os membros de uma equipe de trabalho e por isso um mecanismo de defesa grupal mais eficiente e menos custoso do que tentativas de defesa individuais. Por outro lado, paradoxalmente, um mecanismo de defesa que, justamente por demonstrar a falência de outras tentativas individuais de proteção contra o sofrimento, contribui inclusive para os objetivos da própria organização do trabalho e também para o conformismo, a repetição e a estagnação dos sujeitos.

PALAVRAS-CHAVE: reclamação; discurso; mecanismo de defesa; organização do coletivo de trabalho.

\section{COMPLAINTS IN WORK ORGANIZATIONS: DEFENSE STRATEGY AND EVOCATION OF SUFFERING}

ABSTRACT: This article intends to research the role of complaints in the discourse of workers of work organizations, as seen from Christophe Dejours's theories and central concepts. Based on the conception that work is one of the possibilities of intensely experiencing one's suffering and trying to overcome it, one becomes aware of a creative suffering as a rebellious stance against the organization of work. Complaints evoke suffering as a powerful group bonding strategy whereas the construction of an intersubjective meaning through the ties produced by discourses in the group in the attempt to resist illness as a group. Strong ties of union among the members of a work team result in a group defense mechanism that is more efficient and less expensive than the individual ones. On the other hand, paradoxically, it is a defense mechanism that, demonstrating the failure of other individual attempts of protection against suffering, contributes to the organization's objectives and also to the resignation, repetition and stagnation of the individual.

KEY WORDS: complaint; discourse; defense mechanism; collective work organizations.

Do discurso operário podem-se extrair vários temas que se repetem obstinadamente como um refrão obsessivo. Não há um só texto, uma só entrevista, uma só pesquisa ou greve em que não apareça, sob suas múltiplas variantes, o tema da indignidade operária. Sentimento experimentado maciçamente na classe operária: o da vergonha de ser robotizado, de não ser mais que um apêndice da máquina, às vezes de ser sujo, de não ter mais imaginação ou inteligência, de estar despersonalizado, etc. É do contato forçado com uma tarefa desinteressante que nasce uma imagem de indignidade. A falta de significação, a frustração narcísica, a inutilidade dos gestos, formam, ciclo por ciclo, uma imagem narcísica pálida, feia, miserável ... A vivência depressiva condensa de alguma maneira os sentimentos de indignidade, de inutilidade e de desqualificação, ampliando-os. Esta depressão é dominada pelo cansaço... Executar uma tarefa sem investimento material ou afetivo exige a produção de esforço e de vontade, em outras circunstâncias suportada pelo jogo da motivação e de desejo. A vivência depressiva alimenta-se da sensação de adormecimento intelectual, de aniquilose mental, de paralisia da imaginação e marca o triunfo do condicionamento ao comportamento produtivo" (Dejours, 1992, p.49)

A reclamação recorrente no discurso dos trabalhadores é fato comum nas organizações, como uma manifestação de insatisfação no trabalho. A reclamação, enquanto fato isolado, é pouco citada nos estudos de psicodinâmica do trabalho. A própria insatisfação no trabalho, de modo geral, foi bem pouco estudada até o presente momento, embora,
Christophe Dejours venha analisando exaustivamente o sofrimento psíquico no trabalho.

A corrente dejouriana tomou caminho distinto da psicopatologia do trabalho em 1993, quando se autodenominou psicodinâmica do trabalho. Bastante diferente do modelo de causalidade positivista e cientificista bio-psicossocial do estresse e praticamente sem dialogar com este, a psicodinâmica do trabalho dialoga com as correntes de saúde do trabalhador, com a psicologia ergonômica e com a ergonomia socio-técnica francesa e vai tomar como base, além da psiquiatria social, a psicanálise, a fenomenologia, a sociologia do trabalho e se distanciar de qualquer acepção behaviorista, quantitativa, estatística ou de padronização comportamental. Seus objetivos são de realmente interpelar e flexibilizar as práticas de organização do trabalho contemporâneas. Será levado em conta, a todo tempo, o discurso do trabalhador e seu sofrimento; será considerada também a subjetividade do trabalhador, a intersubjetividade do coletivo de trabalhadores e a subjetividade dos pesquisadores que interpretam o discurso da vivência operária. Sua obra terá forte influência nos trabalhos dos pesquisadores latinos e brasileiros desde a publicação do livro A Loucura do Trabalho (1987).

Este estudo pretende pesquisar a reclamação no discurso dos trabalhadores das organizações na perspectiva de trabalho dejouriana, abrangendo alguns 
dos conceitos principais deste autor. A hipótese é a de que a reclamação no discurso dos trabalhadores vem a ser um mecanismo coletivo de defesa, produzido pela subjetividade resultante dos laços discursivos do coletivo das organizações de trabalho. O enigma, portanto, não se encontra na doença mental. Ele se encontra na forma como os trabalhadores lutam na tentativa de equilibrarem-se, mais ou menos precariamente, na corda bamba do trabalho e nos destinos que estes vão dar a seu sofrimento. Até determinado limite, o equilíbrio psíquico dos trabalhadores é sustentado pela subjetividade do grupo de trabalho, através de mecanismos coletivos de defesa. Rompendose estes limites, independentemente dos motivos que ocasionaram este rompimento, será a singularidade e a história de cada sujeito que irá determinar a temática do distúrbio mental ou psicossomático. A reclamação se mantém, enquanto estratégia coletiva de defesa, como algo necessário, que não se esgota e que se transfere de uma temática a outra, muitas vezes indiscriminadamente, no discurso dos trabalhadores. De fato, a psicodinâmica do trabalho vai nos mostrar, nas próximas páginas, que os esforços das empresas de arrefecer a insatisfação são muitas vezes inúteis: encontrar, desafiar e contornar o sofrimento faz parte da relação do homem com seu trabalho.

\section{Qual Reclamação?}

Ação com significado polissêmico, a reclamação pode ser tanto protesto, reivindicação, oposição, demanda e exigência, como também queixa, lamento, clamor, pedido e descontentamento. Reclama-se nas organizações sobre o chefe, os colegas de trabalho, sobre o salário, as condições de trabalho ou a empresa de modo geral. As reclamações, geralmente, apresentam-se no discurso dos empregados como variações sobre o mesmo tema. Como uma cadeia significante que se retroalimenta permanentemente, quem conta um conto aumenta um ponto ao que o outro diz. A reclamação como posicionamento - ativo ou passivo, de reivindicação ou lamento - permite ao sujeito se estabelecer e se restabelecer no grupo, na medida em que, ao reclamar, ele compartilha com seus pares o fato de a organização do trabalho o fazer sofrer como faz a eles, ainda que a vivência do sofrimento seja algo eminentemente singular.

Reclamar é uma das possibilidades de evocar o sofrimento e a doença através de atos de linguagem comuns aos trabalhadores (Dejours, 2004). Sofrimento criador, portanto, enquanto estado de luta contra a organização do trabalho que muitas vezes conduz ao adoecimento. Por isso, a reclamação é uma forma de vinculação grupal poderosa, como construção de sentido intersubjetivo, na tentativa de resistência grupal à doença. Um forte elo de união entre os membros de uma equipe de trabalho e por isso um mecanismo de defesa grupal mais eficiente e menos custoso do que tentativas de defesa individuais.

A reclamação, no entanto, apresenta uma contradição fundamental: demonstra ser, por um lado, um mecanismo de defesa eficaz - já que mantém o grupo alerta e coeso e, por outro lado, um mecanismo de defesa que já demonstra falência de outras tentativas de proteção contra o sofrimento, contribuindo inclusive com o conformismo, a repetição e a estagnação dos sujeitos. Este é um paradoxo da reclamação ou de qualquer outro mecanismo de defesa no coletivo de trabalho. Elaborados à custa de muito investimento, estratégias e energia dos sujeitos, exatamente para fazer face à organização do trabalho, os mecanismos de defesa podem acabar por se tornar ideologia defensiva que, surpreendentemente, coopera com os objetivos da própria organização do trabalho ao se constituir como uma recorrência que circula em torno das relações de poder. A radicalização dos mecanismos de defesa em ideologia defensiva pode, em seu extremo, acarretar violência nos grupos de trabalho como imaginário perseguidor entre seus membros (Dejours, 1994) que rechaça as diferenças e insiste na homogeneização e na conformidade de condutas e do discurso, conduzindo à alienação. Nessa medida, reclamase repetidamente e insistentemente com o colega e também do próprio colega pela real impossibilidade de romper com a ideologia defensiva, no caso, a reclamação institucionalizada que já serve até a particularismos e conflitos de equipes e desvirtua a atenção de todos do real motivo da reclamação: a organização do trabalho que gera sofrimento.

\section{O Contrato De Trabalho: Terreno De Ambigüidades}

Nas organizações, as subjetividades são fortemente influenciadas pela intersubjetividade do grupo de funcionários. Qualquer que seja o trabalho numa organização, ele no mínimo proporcionará ao sujeito um bem precioso: a possibilidade de identificação social e cultural através da atmosfera de afiliação a grupos e incorporação de valores.

Ainda que haja competição, formação de subgrupos e grupos rivais, eleição de bodes expiatórios, etc, os sujeitos compartilham pela empresa os mesmos sentimentos que os fazem buscar afiliação a grupos: idealização, necessidade de identificação, de valorização e de reconhecimento. Expectativa bastante corroborada pelas próprias organizações, quando estas prometem, subrepticiamente, que ali o sujeito encontrará a realização, a satisfação e a felicidade.

O contracheque ao final de cada mês é a prova cabal e concreta, a metáfora exata de que o excedente da mãode-obra empregado pela força de produção, a mais-valia, é uma sobra incomensurável e impagável pela empresa. Esta, inevitavelmente, reduz nos números e cifras do contracheque o que não pode ser contabilizado e mensurado e que não tem preço para o trabalhador: sua saúde, sua força de trabalho e sua energia criativa.

Acrescente-se a este, outro hiato na organização da força de trabalho como força produtiva: a impossibilidade de haver troca satisfatória nas relações de trabalho. $\mathrm{O}$ contrato trabalhador/empregador é sempre e por princípio incompleto, pois espera-se determinado desempenho do empregado, sem que este saiba exatamente quais serão os desdobramentos e intercorrências de seu esforço no dia-a-dia de trabalho.

O acúmulo de reclamações é uma das reações dos trabalhadores, segundo Townley (2001), diante das tentativas das organizações em suprimir ou esconder suas 
Hallack, F. S. \& Silva, C.O. "A Reclamação nas Organizações do Trabalho: Estratégia Defensiva e Evocação do Sofrimento".

ambigüidades e pretender que elas não existam (as mesmas ambigüidades que a psicodinâmica do trabalho recupera como objeto de estudo). A reclamação tem, sob esta perspectiva, uma face de denúncia da insatisfação, de protesto contra a coisificação do homem nas organizações e de resistência das singularidades em se deixarem massificar.

Há momentos, no cotidiano do trabalho serializado ou com subemprego das aptidões psíquicas, em que a única coisa sobre a qual o sujeito tem realmente ingerência é a possibilidade de reclamar, ainda que as reclamações não sejam mais do que meros monólogos simultâneos, (Grisci, 1999) palavras vazias ou formas tácitas de preservação do não-dito em alguns momentos.

No entanto, e por isso mesmo, como ação que insiste em se fazer representar no discurso dos trabalhadores, a reclamação tem outra face também importante: a de repetição.

\section{Reclamar, Repetir e Elaborar}

Repetir é necessário na vida humana. Não por acaso recebe status de uma compulsão em psicanálise. A repetição está a serviço da recordação das experiências infantis.

Os conteúdos recalcados e os afetos vinculados a estes conteúdos nunca mais serão efetivamente recuperados pelo sujeito. Ele se submete à compulsão à repetição, que substitui a possibilidade de recordar em praticamente todas as relações objetais do mesmo. É o que a psicanálise chama de transferência: um fragmento da repetição, e esta por sua vez, uma transferência do passado esquecido.

O sujeito ao repetir, no entanto, ao invés de recordar, atua sob as condições da resistência. Quanto maior a resistência, mais extensivamente a atuação (repetição) substituirá o recordar, porque o recordar ideal do que foi esquecido corresponde a um estado no qual a resistência foi posta completamente de lado.

A repetição gera sofrimento e, paradoxalmente, resistência em abrir mão do sofrimento. O sujeito freqüentemente lamenta em demasiado ou até subestima a importância da doença. Estendeu às manifestações dela (seus sintomas) a mesma política de repressão que adotara em relação às suas origens (Freud, 1989).

O grande desafio, ao longo da vida, através da repetição, é reencontrar o sofrimento e dominá-lo. Portanto, não se busca arrefecê-lo exatamente “... porque os trabalhadores, se investem esforços impressionantes para lutar contra o sofrimento, não procuram situações de trabalho sem sofrimento." (Dejours, 1996, p.160) O trabalho atende às exigências de trabalho das pulsões (sublimação) e às exigências de trabalho do sofrimento criador. Muitas tentativas e erros serão necessários para que o sujeito reencontre nos desenlaces cotidianos do trabalho respostas para suas perguntas, a sensação de prazer e o sentido da sua produção para a coletividade e, portanto, muito investimento pulsional que, inevitavelmente, vai esmorecer em determinados momentos e insistir em se representar novamente em futuras tentativas.

No entanto, o trabalho pode também, ao invés de atender à repetição das necessidades pulsionais, sucumbir à necessidade de repetir pura e simplesmente, não viabilizando a sublimação e produzindo sofrimento patogênico. Neste caso, o sujeito transfere para o campo do trabalho suas pulsões patogênicas recalcadas através de seus sintomas e não da sublimação, pois “... a sublimação é fundamentalmente uma operação de subversão do sofrimento que recomeça sempre, que destaca o sofrimento de sua origem e elimina a repetição" (Dejours, 1996, p. 160). Um circuito que se fecha e retorna a seu início continuamente, gerando motivação e prazer no trabalho e fortificando a identidade do sujeito desde que todos os seus elementos estejam presentes:

A via psíquica é a primeira alternativa de descarga das excitações vindas do interior ou do exterior, seguida pelas vias motoras e viscerais, e assim sucessivamente. Por isso,

Sofrimento criador $\Rightarrow$ repetição $\Rightarrow$ sublimação $\Rightarrow$ sentido $\Rightarrow$

eliminação da repetição $\Rightarrow$ reconhecimento e identidade

a princípio, desde que o trabalho seja desafiador e tenha aproximações simbólicas com a história de vida do sujeito, é comum que a via psíquica seja sua via de descarga preferencial. De fato, reclama-se menos ou mais dependendo da organização de trabalho e da organização (estabelecimento) em que se trabalha. Há pessoas que inclusive encontram seu equilíbrio psíquico somente porque executam trabalhos que lhes dão acesso à criatividade, à sublimação e ao reconhecimento.

Não por acaso, portanto, a temática mais freqüente da reclamação gira em torno do reconhecimento ou da injustiça supostamente cometida pela falta dele, ainda que muitas empresas lancem mão de entrevistas de avaliação, avaliações de desempenho, gestão por objetivos, etc, como métodos de controle e medição que visam também dar retorno ao empregado sobre seu desempenho, mas que podem gerar mais insatisfação, concorrência, rivalidade e comportamentos desleais entre colegas. Além disso, quando a execução da tarefa, compartimentada ou não, vem separada da concepção e demanda rigidez na sua condução, o trabalhador tende a tentar eliminar as formas de presentificação do sofrimento criador (imaginação, fantasias, devaneios...) geralmente acelerando o ritmo de trabalho, a fim de preencher seu campo de consciência estritamente com o conteúdo da mesma. Este mecanismo de defesa gera torpor, paralisação e anestesia psíquica. Suprime-se a imaginação e a atividade fantasmática. A repressão da pulsão que não se faz representar no aparelho psíquico encontra freqüentemente descarga direta no corpo e, portanto, em doenças físicas.

Ao reclamar do outro, seja o outro a empresa, o chefe ou o colega, permanece-se no âmbito da palavra, da linguagem e, portanto, da tentativa de elaboração. Por isso, provavelmente, fantasia-se sobre o que o outro quer, sobre o que é preciso fazer para ser reconhecido e valorizado para além da redução dos números do contracheque. Reclamando, repetindo e elaborando, o sujeito se pergunta qual é o desejo do outro para que 
possa ser reconhecido, ou, mais do que isso, qual é o seu próprio desejo para que possa dar cabo a vivências sublimatórias.

Para aqueles que investem afetivamente em seu trabalho, suportado, portanto, pelo desejo, o lugar da reclamação tende a ser menos difuso, mais localizado, mais pontual, provavelmente visando de fato promover mudanças em nível macro da organização da empresa e da organização de trabalho. Poderíamos dizer, - de acordo com a concepção de trabalho como enigma preconizada por Dejours, que concebe o sofrimento como patogênico e criador - que quando o desejo está em jogo, há sofrimento criador e mediador para a saúde. Quando o desejo está a nocaute no embate de forças há sofrimento patogênico: a organização de trabalho oferece limites rígidos e precisos à transformação e, tudo o que havia disponível já foi tentado em termos de gestão, transformação e aperfeiçoamento, o que resta é um sofrimento constante e residual manifestado no tédio, na repetição, na frustração e no aborrecimento, que têm na reclamação seu conteúdo manifesto no discurso dos trabalhadores, exatamente como psicopatologia da normalidade, de coesão e de consenso grupal.

Quando não há autogestão e trabalho criativo acarretando subemprego de aptidões psíquicas, fantasmáticas ou psicomotoras. há geração de carga psíquica negativa, tensionamento, retenção e até, surpreendentemente, fadiga no trabalho. Quanto maior for a carga psíquica negativa não descarregada - por subemprego ou, contrariamente, elevada pressão e demanda da organização de trabalho - maior tenderá ser a reclamação, pois esta tentará fazer jus à tentativa de atividade fantasmática. Se não for declaradamente reprimida pela empresa, a reclamação propicia a possibilidade de o sujeito inserir algo da sua singularidade no trabalho compartimentado ou pré-determinado por outrem - algumas vezes até mesmo concomitantemente à execução da tarefa. É uma tentativa de preservar uma última possibilidade de descarga psíquica das representações mentais suprimidas, encontrando esteio e incentivo no compartilhamento do sofrimento nos jogos lingüísticos comuns aos pares e até, por extensão, fora do trabalho, com os familiares e amigos. Neste caso, a reclamação pode funcionar, até mesmo, como uma possibilidade fantasmática substitutiva que se subtrai do desejo do sujeito reprimido por seus superiores e por ele próprio no trabalho segmentado e na realização da tarefa.

Esse caráter de quebra do silêncio da reclamação é fundamental. Seja do silêncio que foi imposto ao desejo para execução da tarefa, seja do silêncio muitas vezes manifestamente demandado pela organização do trabalho. Ao reclamar, denuncia-se a falácia da tentativa de motivação comportamental pela organização; enfrentamse as regras, transgride-se o controle.

Por negação ou eufemização, o tom do discurso pode até ter inclusive o tom da brincadeira, do sarcasmo e da galhardia, instrumentos poderosos para vencer o tédio segundo Brant e Minayo-Gomez (2004).

Reclamar e brincar dentro da organização são práticas, contíguas ou não, amplamente legitimadas, difundidas e consensuais nos grupos de trabalho, com a única diferença que a brincadeira não traz, aparentemente, o tom do trágico, do insuportável que a reclamação suscita. Ela reproduz a capacidade de jogar aprendida na infância, tempo em que a angústia e o sofrimento primeiros eram vivenciados preferencialmente pela via lúdica.

A reclamação tem também a face de irritação diante da repressão do desejo sob a máscara da necessidade de motivação. Para Dejours,

\begin{abstract}
A nova interpretação das relações subjetivas da organização do trabalho revela a existência de contradições e de impossibilidades materiais contidas na organização prescrita do trabalho. Diante dessas dificuldades da organização do trabalho, cada qual contribui em segredo com ajustes e com estratégias, o que provoca o surgimento das contradições entre as pessoas. Não se podendo imputar essas contradições à organização do trabalho mesma, elas degeneram em conflitos interpessoais, cada qual sendo tachado pelo outro como o responsável pelas imperfeições do trabalho e pelos riscos de segurança pessoal que cada um corre em decorrência desse trabalho malfeito. (Dejours, 2004, p.218)
\end{abstract}

Ainda que seja para se queixarem uns dos outros, a reclamação demonstra a necessidade e a tentativa de reinscrever o sentido pelo menos na fala compartilhada dos trabalhadores, enquanto não é possível fazê-lo na própria organização do trabalho. Ela despressuriza a energia pulsional retida, canaliza a irritação e resiste à violência simbólica e real que foi instalada sobre o corpo. Algo que escapa ao próprio sujeito permanentemente, que o leva a não querer parar de reclamar e até a não se perguntar o porquê da reclamação.

Neste ponto, reinstala-se novamente o paradoxo fascinante da reclamação como possibilidade transgressiva e refrão obsessivo (Dejours, 1992, p.49) que nos levará novamente às suas contradições e que não nos conduzirá a um sentido unívoco a título de conclusão.

\section{Conclusão}

Há dúvidas - principalmente em se tratando da cultura brasileira, acostumada a reportar-se predominantemente a especialistas (Coimbra, 1994) - se reclamar fora da empresa no sentido de reivindicar - fora dos parâmetros judiciais - é prática lícita, mas não há dúvida de que dentro da empresa é uma prática profícua fomentada justamente por ser considerada, esta, local de indignidade, inutilidade e desqualificação. Esta noção, no entanto, que não é percebida como tal, ao se apropriar do discurso e da ideologia defensiva da equipe de trabalho no contexto específico daquele microcosmo de práticas discursivas e poder relacional, é para o sujeito uma legitimação, um balizamento de se falar do sofrimento sem ser estigmatizado pelo grupo.

Caso a produção de recursos psíquicos coletivos seja dificultada e o sujeito, por algum motivo, se desvincule dos laços discursivos coletivos, este pode caminhar para a descompensação mental ou para a doença psicossomática. $\mathrm{O}$ rompimento radical, manifestado na doença de um dos elementos do grupo, expõe e denuncia 
Hallack, F. S. \& Silva, C.O. "A Reclamação nas Organizações do Trabalho: Estratégia Defensiva e Evocação do Sofrimento".

a fragilidade e a ineficiência dos mecanismos de defesa utilizados. Rompe-se a regra, o consenso, o acordo, a fala compartilhada. O indivíduo doente pode não ser mais reconhecido pelo grupo e poderá ser rejeitado como ícone de um fracasso que o grupo não deseja admitir. Portanto, enquanto o sujeito ainda está reclamando junto ao grupo de trabalho e tomando a linguagem e o vocabulário do outro para falar sobre o sofrimento e o medo próprios, escapa-se da possibilidade de ser enquadrado como e, até mesmo, de se tornar doente ou deprimido. Medo e tristeza não viram necessariamente, desta forma, fobia e depressão. Segundo Dejours, “... a linguagem não é apenas o meio de elaboração coletiva das experiências vivenciadas: é ainda um operador de construção do próprio coletivo..." (Dejours, 2004, p.93).

A preciosidade da reclamação enquanto mecanismo de defesa encontra-se no fato desta estar inscrita no campo simbólico e do discurso, lançando mão da via de descarga psíquica dos trabalhadores e da elaboração mental. Sua contradição fundamental e intrigante é mesmo seu destino inevitável de alienação, na medida em que, sua face social inscreve-se nas subjetividades de cada indivíduo e na necessidade pulsional primordial de recordar, repetir e elaborar suas experiências individuais, traumáticas ou não.

Isto poderia nos levar a concluir que, se tomada somente enquanto manifestação do coletivo de trabalhadores como evidência das contradições da organização prescrita do trabalho, sendo desta forma mantenedora da coesão grupal e da fala compartilhada, a reclamação seria uma forma de crítica à alienação? Mais do que isso, ela teria este caráter crítico puro somente até esbarrar com a face transferencial singular com que cada trabalhador lida com o trabalho que o remete inevitavelmente à repetição - ou, à sublimação na melhor das hipóteses - conduzindo ao estancamento, à estagnação e à anestesia para práticas de cidadania e de ações políticas em prol das classes trabalhadoras?

Não, não podemos absolutamente afirmar isso. Isto porque, a reclamação, enquanto tentativa de eufemização dos constrangimentos e do sofrimento no trabalho, leva a termo sua finalidade, espantando muitas vezes o tédio e propiciando até mesmo que a queixa e lamento apareçam de forma lúdica. Além disso, como outros mecanismos coletivos de defesa, adquire mais força ao se radicalizar em ideologia defensiva, o que acaba por servir à própria organização do trabalho: as pessoas reclamam, mas não deixam de executar a tarefa da melhor forma que podem apesar de todas as contradições presentes na mesma, e muitas vezes acabam por reclamar mais dos colegas do que, propriamente, da empresa em questão.

Portanto, a reclamação, enquanto mecanismo de defesa, canaliza a irritação preservando a execução da tarefa, mostrando por isso, ser uma genuína manifestação da psicopatologia da normalidade no trabalho. Enquanto ideologia defensiva ela vai exatamente ao encontro do medo que conduz à banalização da injustiça social (Dejours, 2003).

A ameaça permanente, e a real precarização das relações de trabalho na atualidade, faz com que o trabalhador aumente a cadência na execução da tarefa, como tamponamento da falta de sentido e da busca desenfreada por reconhecimento. Neste caso, não o reconhecimento salutar que conduz à produção de sentido e à sublimação, mas o reconhecimento que irá salvar seu emprego e supostamente o salvaguardar da fatalidade a qual muitos sucumbiram ao acabar nas ruas esmolando (se tomarmos como exemplo, o caso brasileiro). A busca pelo reconhecimento não encontra mais a via de descarga que conduz à identidade e à integração da história de vida do sujeito transferida para o seu trabalho o que, por sua vez, o remete, na sua qualidade de campo transferencial privilegiado, ao seu tempo, à sociedade em que vive, aos acontecimentos históricos e mundiais dos quais é parte integrante.

Sai de cena então o sofrimento criador, ficando em cena somente o sofrimento patogênico que demanda do sujeito não a inteligência astuciosa e transgressiva, não a busca de sentido para si próprio e sua vida, não a consciência crítica de sua condição; mas, sim, a necessidade de se defender cada vez mais de uma ameaça iminente. As estratégias defensivas enquanto ideologias de defesa são resistências construídas por um processo de alienação que exigem uma negação coletiva ou uma construção fantasiosa coletiva sobre o mundo real e os reais problemas do trabalho. Como em toda anestesia, paralisa-se momentaneamente a indignação e o movimento - principalmente em sociedades em que a acumulação de riqueza e a multiplicação da miséria se dão de forma cada vez mais aguda - mas as capacidades para tal permanecem intactas. (Dejours, 2003). Para Dejours,

\begin{abstract}
... todas as formas clássicas de solidariedade estão em processo de desestruturação - e não apenas as estratégias coletivas de defesa. Diante dos constrangimentos do trabalho, todos se encontram, psicologicamente, cada dia mais só... Todas as novas patologias relacionadas com o trabalho, hoje, são, antes, patologias da solidão. (Dejours, 2004, p.17)
\end{abstract}

A cooperação não é prescritível, ao contrário do que muitas correntes de gestão em recursos humanos tentam praticar. A alienação do trabalhador quanto à concepção e gestão da organização do trabalho e o não reconhecimento das suas contribuições e dos seus esforços na tentativa de criação, ajustes e adequação das técnicas, têm papel fundamental na desmobilização dos cidadãos, no afrouxamento dos vínculos de solidariedade e no recrudescimento das patologias da solidão nas sociedades industrializadas, capitalistas e agora globalizadas.

Devido a esta intermediação fundamental do trabalho entre o real e a sociedade, Dejours afirma que “... não há articulação direta entre sujeito do inconsciente e campo social. Esta relação é sempre mediada pela referência de uma ação sobre o real que mobiliza a atividade do trabalho." (Dejours, 2004, p.75). A linguagem que se presentifica na reclamação com o outro, é um vigoroso meio de perlaboração, de se tentar alcançar a inteligibilidade da práxis do trabalhador, pois "a inteligência e a engenhosidade da ação estão à frente da consciência que os agentes têm delas" (Dejours, 2004, p.58). Trabalho e linguagem são, portanto, conceitos chave 
para se pensar a articulação entre o sujeito e a sociedade, sendo que o segundo possui maior prestígio nos meios acadêmicos e científicos.

Este estudo procurou ampliar, portanto, o papel do trabalho na construção da identidade do sujeito, como resultante exatamente de um processo de subversão das determinações biológicas e sociais, a partir da multiplicidade de objetos de investimento pulsional e da exigência de trabalho das pulsões que se fazem representar nestes objetos através das organizações do trabalho; e também, através da busca do sujeito por um trabalho que se compatibilize com sua história, que permita o reencontro com seu sofrimento e com isso possibilite vivências sublimatórias, além da legitimação do reconhecimento dos pares e superiores pelo próprio sujeito.

Isso quer dizer que é não qualquer objeto que satisfaz a pulsão e conduz ao sentido. É necessário o reconhecimento do sujeito do reconhecimento do outro. $\mathrm{O}$ reconhecimento do reconhecimento. Não se trata desta forma de qualquer outro e, por isso, o processo de reconhecimento não é algo matemático e previsível como conduzem muitas vezes as empresas. Está de posse somente do sujeito escolher onde, como, porque e quem vai reconhecê-lo para, somente a partir daí, autorizá-lo e legitimá-lo para tal. Esta visão reverte totalmente a concepção de um sujeito passivo e condicionado que deve ser perfeitamente adulado, após executar bem a tarefa para ser recompensado. Deseja-se sempre imprimir uma marca na tarefa que se executa - qualquer que seja ela uma marca pessoal e intransferível. Daí a derrota do sujeito muitas vezes, sucumbindo à perda - ou a não possibilidade de encontro - de sua identidade e, portanto, caminhando para a doença mental.

De fato, encontrar a ocasião propícia e facilitadora para tal engenhosidade entre a pulsão, o desejo, o sentido e o trabalho, pode se tratar de algo raro e evanescente - ainda mais em se tratando da forma em que as organizações de trabalho do modo de produção capitalista se arregimentam.

Que se reclame, então! Lamente-se, proteste-se, reivindique-se, demonstre-se descontentamento! - com todos os riscos de estagnação a que esta ação possa contraditoriamente conduzir. É uma saída mais salutar, pelo que pudemos apreender neste estudo, do que o silenciamento, a repressão das idéias, a aceitação passiva do que é imposto. E muitas vezes, cabe dizer finalmente, mudanças são levadas a cabo porque as reclamações que ecoam nas paredes das organizações tomam forma, ganham voz, chegam no destino certo e são, efetivamente, escutadas.

\section{Referências}

Brant, L.C. \& Minayo-Gomez, C. (2004). A transformação do sofrimento em adoecimento: do nascimento da clínica à psicodinâmica do trabalho. Ciência e Saúde Coletiva, 9(1), 213-223.

Coimbra, C. (1994). Cidadania e processos de inclusão e exclusão social: a construção da identidade. Revista do Departamento de Psicologia UFF, 6(1,2), 1-8.

Dejours, C. (1992). A loucura do trabalho: estudo de psicopatologia do trabalho. São Paulo: Cortez-Oboré.

Dejours, C. (1996). Uma nova visão do sofrimento humano nas organizações. Em J.F. Chanlat (Org.), $O$ indivíduo na organização: dimensões esquecidas (Vol. 1, pp. 149 -174). São Paulo: Atlas.

Dejours, C. (2003). A banalização da injustiça social. Rio de Janeiro: FGV.

Dejours, C. (2004). Addendum: da psicopatologia à psicodinâmica do trabalho. Em S. Lancman \& L.I. Sznelwar (Org.), Christophe Dejours - Da Psicopatologia À Psicodinâmica do Trabalho (pp. 47 - 104). Rio de Janeiro: Fiocruz.

Dejours, C., Abdouchele, E. \& Jayet, C. (1994). Trabalho e saúde mental: da pesquisa à ação. M.I.S. Betiol (Org.), Psicodinâmica do Trabalho: Contribuições da Escola Dejouriana à Análise da Relação Prazer, Sofrimento e Trabalho (pp. 45 - 65). São Paulo: Atlas.

Dejours, C., Dessors, D. \& Desrlaux, F. (1993). Por um trabalho, fator de equilíbrio. Revista de Administração de Empresas, 33(3), 98-104.

Freud, S. (1989). Recordar, repetir e elaborar. Em J. Salomão (Org.), Obras Psicológicas Completas de Sigmund Freud (Vol.XII). Rio de Janeiro: Imago.

Grisci, C. (1999). Trabalho, tempo e subjetividade: impactos da reestruturação produtiva e o papel da psicologia nas organizações. Psicologia, Ciência e Profissão, 19(1), 2-13.

Townley, B. (2001). Conhecimento e Poder nas Organizações. Em E. Davel \& S. Ergara (Org.), Gestão de Pessoas e Subjetividade (pp. 117-143). São Paulo: Atlas.

Fernanda Sansão Hallack fez pós-graduação da Pontifícia Universidade Católica do Rio de Janeiro. Endereço: Rua Marquês de São Vicente, 225 22453-900 Gávea Rio de Janeiro RJ.

E-mail: fernanda@travessa.com.br

Claúdia Osório da Silva é docente vinculada ao Programa de Pós- Graduação em Psicologia da Pontofícia Universidade Católica do Rio de Janeiro E-mail: claudiaosorio@terra.com.br

Fernanda Sansão Hallack e Claudia Osório da Silva

A reclamação nas organizações do trabalho: estratégia defensiva e evocação do sofrimento.

Recebido: 03/11/2005

$1^{\text {a }}$ revisão: $20 / 12 / 2005$

Aceite final: 05/01/2006 